\title{
Reconciliation of research on forest carbon sequestration and water conservation
}

\author{
Tanzeel Javaid Aini Farooqi ${ }^{1}$ Xuhua $\mathrm{Li}^{2} \cdot \mathrm{Zhen}_{\mathrm{Yu}^{3}}$. \\ Shirong Liu ${ }^{4}$ Osbert Jianxin Sun ${ }^{1}$
}

Received: 29 April 2020 / Accepted: 4 May 2020 / Published online: 11 May 2020

(C) The Author(s) 2020

\begin{abstract}
Carbon sequestration and water conservation are two of the key ecosystem services that forests provide for societal need to address environmental issues. Optimization of the dual services is the ultimate goal in forest management for mitigating global climate change and safeguarding terrestrial water balance. However, there are some tradeoffs between gain in forest productivity and ecosystem water balance. We conducted literature review based on published articles for learned knowledge on forest carbon fixation and hydrological regulations. Some knowledge gaps and research needs are identified by examining the inter-connections between forest carbon sequestration and water conservation. Past researches have helped gain basic understanding of the mechanisms and controls of forest carbon fixation and
\end{abstract}

Project funding: This research was funded by Ministry of Science and Technology of China (Grant No. 2016YFC0502104).

The online version is available at http://www.springerlink.com.

Corresponding editor: Yu Lei.

Osbert Jianxin Sun

sunjianx@bjfu.edu.cn

1 School of Ecology and Nature Conservation, Beijing Forestry University, Beijing 100083, People's Republic of China

2 Sichuan Academy of Forestry, Chengdu 610081, People's Republic of China

3 School of Applied Meteorology, Nanjing University of Information Science and Technology, Nanjing 210044, People's Republic of China

4 State Forestry and Grassland Administration of China Key Laboratory of Forest Ecology and Environment, Institute of Forest Ecology, Environment and Protection, Chinese Academy of Forestry, Beijing 100091, People's Republic of China hydrological regulations as two separate issues. Tools and approaches are well established for quantifying and monitoring forest carbon and hydrological issues, operating at different spatial and temporal scales. There are knowledge gaps on how to design afforestation schemes facilitating enhanced ecosystem services in forest carbon sequestration and water conservation. For the top-down planning of afforestation in regions where water availability is anticipated to be problematic, the questions of how much and where to plant for given land availability, known environmental implications, and sustained regional development and livelihood need to be addressed. For local management considerations, the questions of what and how to plant prevail. Efforts are needed in joint studies of forest carbon sequestration and water conservation functionalities, specifically in relation to establishment and management of planted forests aiming for delivering regulatory ecosystem services in carbon sequestration, water conservation and other social values. We propose an integrated framework with dual consideration of carbon sequestration and water conservation in forest management for future research pursue.

Keywords Carbon balance $\cdot$ Ecosystem services $\cdot$ Forest management $\cdot$ Hydrological processes $\cdot$ Tradeoff

\section{Introduction}

Forests are well recognized for their role in provisioning of ecosystem services (Costanza et al. 1997), of which carbon sequestration and water conservation are of key considerations in contemporary forest management due to concerns on global climate change and water resources safety. While expansion of forests is favored for enhanced terrestrial carbon sequestration and increased overall ecosystem services 
globally, establishment of large-scale plantation forests involves tradeoffs for decreased local water availability (Jackson et al. 2005; Doelman et al. 2020) and reduced streamflow (Trabucco et al. 2008; Zhang et al. 2017b). Such tradeoffs are of particular concern in regions with water scarcity and periodic drought problems (Malmer et al. 2010; Matyas and Sun 2014; Schwärzel et al. 2020). However, in regions where water is non-limiting, forests play a regulatory role on local water cycle by temporarily retaining rainwater through either improved water infiltration in soil or increased water storage in litter layer, thereby avoiding immediate runoff water losses (Wu et al. 2020).

In views of the natural sustainability issues and societal expectations, planning and management of plantation forests require sound knowledge of the technical measures gaining optimized socioeconomic benefits while minimizing or facilitating environmental impacts. In traditional forestry, wood harvesting, tree regeneration and forest protection are three core objectives of forest management. Behind various forest management activities in support of those objectives are active research efforts targeting the delivery of desirable forest products (Fig. 1). Realizations of the vital roles of forests in environmental regulations and eco-safety have promoted the development and management of plantation forests for non-timber products and/or services in modern forestry (Haakana et al. 2020; Temperli et al. 2020). Increased carbon sequestration capability and effective water conservation benefits are two of the key services highly regarded for forest ecosystems ( $\mathrm{Li}$ et al. 2019). Over the decades, numerous studies have been conducted to quantify the capacity and controls of forest carbon sequestration, and to determine the regulatory roles of forests in local and regional water cycles.
Fig. 1 Linkage of traditional forestry research to forest management

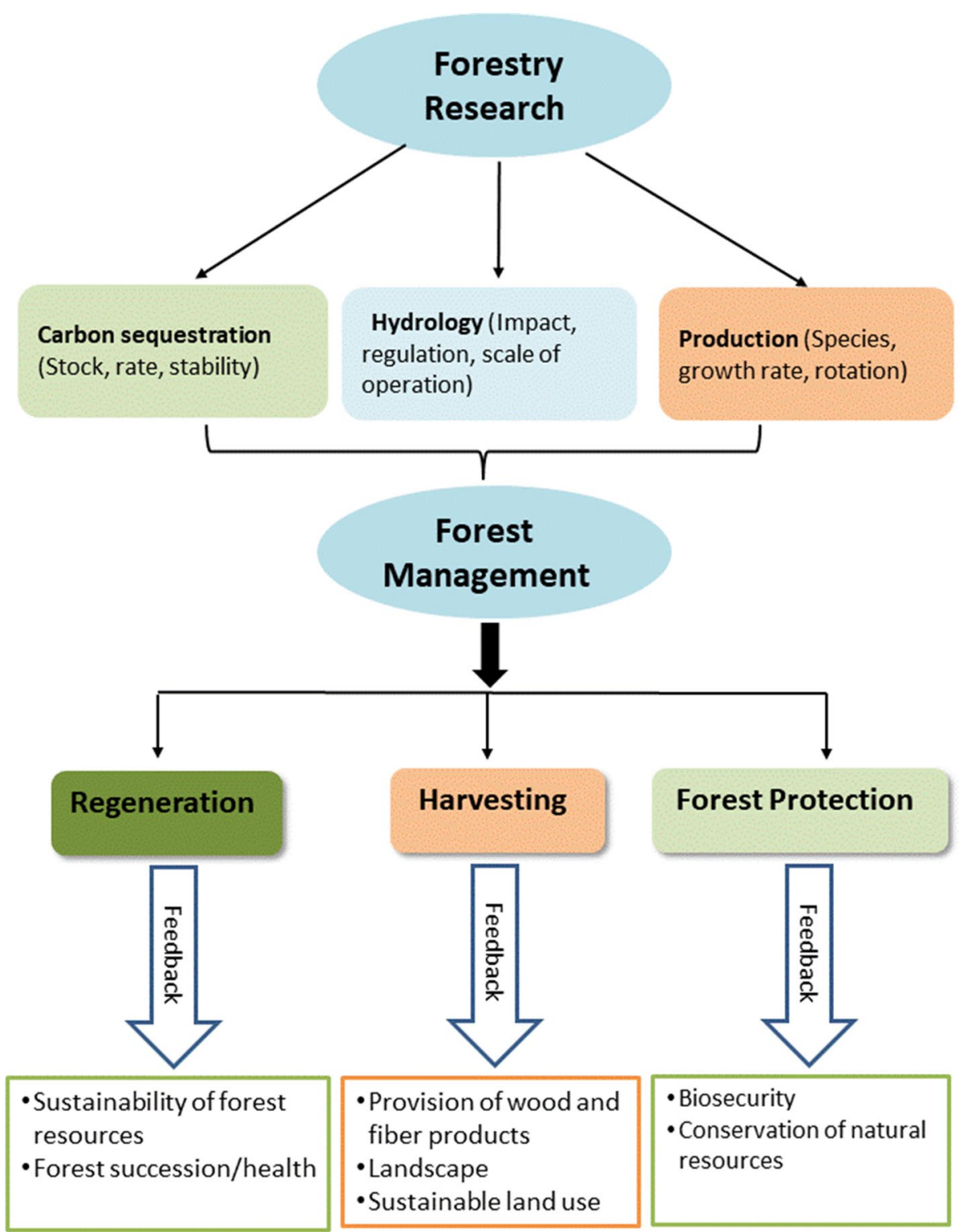


Search of Web of Science for papers published in 1985-2020 using the key words "forest + carbon" yielded 84,752 results; the number of results reached 101,633 under the search for "forest + water use", and 13,413 under "forest + hydrology". Search for "forest + carbon + water use" produced 26,823 outcomes, and 2556 for "forest + carbon + hydrology".

This review examines some of the learned knowledge and current development in forest carbon fixation research and studies of forest hydrological processes. Our aims are to identify key knowledge gaps in understanding the interconnections between forest carbon sequestration and water conservation, and to develop a framework for future forest research and management with dual consideration of carbon sequestration and water conservation.

\section{Forest carbon sequestration}

Forest plants fix and store carbon in biomass, woody debris, litter and soils. Earlier research on forest carbon stocks has been predominantly concerned with development of tools and approaches in quantifying forest carbon stocks and their partitioning in various carbon pools, as well as in identifying the spatiotemporal variations in forest carbon fixation and controlling factors. Traditional estimations of forest carbon stock and its changes include harvesting and modeling methods. Direct harvesting of trees involves measurements of different tree components, such as trunk, leaves, branches, and roots (Zhou et al. 2019; Sun and Liu 2020). Soils were also sampled to provide full accounting of forest ecosystem carbon stock (Tang et al. 2018). Although the traditional approach provides the most accurate estimates of carbon stock, it is generally costly, labor intensive, time consuming, and sometimes impossible due to poor accessibility. A less intensive approach is to calculate forest carbon stock using allometric equations. Allometric equations for biomass estimation are developed by establishing a relationship between biomass and the various physical parameters of the trees such as the diameter at breast height, tree height, crown diameter, and tree species (Vashum and Jayakumar 2012). By incorporating forest inventory data and biomass prediction equations of different tree species, researchers are able to assess regional or national carbon stocks (Law et al. 2004). Forest carbon stock changes (fluxes) can also be quantified if repeated inventory data are available (e.g. Fang et al. 2001).

The development and applications of remote sensing products of vegetation and ecosystem process modelling, combined with site measurements and forest inventory data, have allowed cost-effective, large scale studies of forest carbon budgeting and underpinning the factors contributing to spatiotemporal dynamics of forest carbon stocks. The applications of remote sensing approach can be classified into two groups: one for assessing forest biomass carbon stock and the other for depicting forest carbon changes (fluxes). In the area of forest carbon stock assessment, many studies were conducted to build relationships between satellitederived index with ground-based biological measurements, and then extrapolating the relationship spatially to obtain regional estimates. Satellite data for forest biomass carbon stock assessments are collected from passive (multispectral, hyper-spectral sensors) and active (light detection and ranging [LiDAR], and radio detection and ranging [radar] sensors) remote sensing techniques. Passive remote sensing relies on reflection signals of land surface from solar radiation, which is therefore operational at local to global scales (Timothy et al. 2016). Nonetheless, this approach is more sensitive to crown surface than below-canopy factors, rendering forest biomass less capable to be captured in dense forests as the reflected signals saturated (Tucker and Sellers 1986). Active remote sensing, on the other hand, retrieves signals emitted from airborne instruments for forest biomass reconstruction. Active remote sensing techniques are advantaged in providing forest structure information (e.g. tree height, crown area, and trunk size) regardless of the weather condition, which is the known challenge in passive remote sensing. Forest carbon fluxes are quantified using satellite-derived index as a pivotal driving factor. Light use efficiency model is the most typical tool for developing satellite-derived vegetation index, such as CASA, VPM, and GIO-PEM. It predicts net primary productivity (NPP) assuming directly proportional relationship between vegetation carbon uptake and the absorbed photosynthetically active radiation (APAR) (Medlyn 1998). Due to the simplicity of light use efficiency model, it can be easily extrapolated to regional and even global scales.

Despite the superiority in delineating macro-scale vegetation activity, remote sensing approach is limited to produce carbon fluxes and aboveground biomass carbon using simplified, empirical models. While in comparison, underground soil carbon stock and dynamics were less capable to be directly obtained from satellite observations. Integrating ground-based biological measurements, remote sensing data, and ecosystem modelling has proven an effective approach of quantifying regional forest carbon stocks and balances (Law et al. 2004).

Many factors affect the density and partitioning of carbon in forest stands. Continentally and globally, climate appears to the most important factor shaping the spatial patterns of forest carbon stocks (Pan et al. 2011; Zhou et al. 2019), and locally and regionally, the density and partitioning of forest carbon varies with tree species, forest structure and types, stand development, management, and soil conditions (Giardina and Ryan 2000; Law et al. 2004; Sun et al. 2004; Li et al. 2019). Marked differences can been found in forest carbon in relation to forest types, development, 
and site conditions regionally (Law et al. 2004) and at landscape-scale ( $\mathrm{Li}$ et al. 2019), and between natural and planted forests (Yu et al. 2019). Natural and anthropogenic disturbances, accidental or intentional, are all detrimental to the stock and stability of forest carbon pools. While wood harvesting and fire cause instant removal of forest biomass carbon, chronical events such as insect outbreak and drought also lead to variable impacts on the fixation and cycling of forest carbon (Pregitzer and Euskirchen 2004). Harvestrelated increases in decomposition affect the $\mathrm{C}$ budget over the entire harvest cycle (Noormets et al. 2015). Fire can have differential roles in affecting forest biomass carbon and soil carbon; it reduces biomass carbon by burning down the trees, and modifies carbon pools. The occurrence of black carbon produced by fire alters SOC composition in favor of enhanced recalcitrance. It is considered that, through proper ecosystem management and wood utilization, some forests have potential for enhanced carbon sequestration (Boisvenue et al. 2012; Lempriere et al. 2013). Recent studies also show that fast urbanization in China strongly increased forest soil carbon sequestration at urban center (Zhai et al. 2017; Lv et al. 2018), possibly owing to soil fungal-related carbon and soil carbon turnover rate (Wang et al. 2019b, 2020). Landscape-level configuration could improve forest ecosystem stability and favor tree growth and carbon sequestration (Zhang et al. 2017a, b; Yang et al. 2019; Zhao et al. 2016).

Recent studies of forest carbon sequestration have been oriented in uncovering the hidden box of carbon pools, i.e. soil carbon. In majority of the forest stands, only about a third of carbon are stored in living plants as biomass; the remaining two-thirds are in soils as SOC and litter (Law et al. 2004; Sun et al. 2004). Soil carbon retention and stability have emerged as of recent research interest (You et al. 2014; Wang et al. 2015, 2019a; Sun et al. 2019). Soil organic carbon storage and turnover are affected by climate, management, and disturbance, leading to spatial and temporal variations (Giardina and Ryan 2000; Schuur et al. 2001). The stability and long-term stores of soil organic carbon may be determined by chemical recalcitrance and physical protection of carbon compounds and complexing (Sollins et al. 1996; Wang et al. 2019a). Soil organic carbon is generally better preserved in humid soils and under low temperatures (Schuur et al. 2001; Sun et al. 2004, 2019). Returning farmland to larch forests has been shown to increase carbon in mineral soils at a rate of $100 \mathrm{~g} \mathrm{~m}^{-2} \mathrm{a}^{-1}$ (Wang et al. 2011), which is a significant addition to carbon sequestration in aboveground biomass. Different species showed different capacities in its carbon sequestration, and soil nutrient utilization, indicating proper species could shape forest's carbon sink size in mineral soils, especially in the deep soil layers (Wang et al. 2014, 2017; Wu et al. 2019).

On the ecosystem service of forest carbon sequestration, research to date well supports the scaling up of forest carbon stock and fluxes from stand level to regional and global scales (Law et al. 2004; Pan et al. 2011; Zhou et al. 2019).

\section{Forest water relations and hydrological processes}

While expansion of planted forests is viewed as a favorable option for mitigating greenhouse gas emission and delivering multiple ecosystem services, there are increasing concerns on the potential risks of large-scale afforestation to regional water securities in drylands (Doelman et al. 2020; Schwärzel et al. 2020). Forests are known for their requirements of sufficient water supplies and roles in hydrological regulations. However, unlike carbon sequestration, the scale-dependent forest water relations and hydrological processes are less understood due to mostly technical difficulties in observational studies. Although the effects of forest cover change on water resources has been investigated at different scales using various methods, a consensus on the conclusion remains an open question due to enormous discrepancies between studies (Brown et al. 2007; Bosch and Hewlett 1982; Sun et al. 2006; Trabucco et al. 2008). Experimental observations at the watershed scale reflect a "bottom-up" approach in examining the role of forests in hydrological regulations. For small watersheds $\left(<1000 \mathrm{~km}^{2}\right)$ that have been intensively studied, a general agreement is that forest cover loss/gain increase/reduce annual runoff (Zhang et al. 2017b). While in comparison, large watersheds $\left(>1000 \mathrm{~km}^{2}\right)$ are more complex but much less examined due to data limitation and confounding factors (e.g. climate variability, urbanization, dam construction; Zhang et al. 2017b). Modeling using energy-based equations or waterbalance simulations represents "top-down approach" (Zhou et al. 2015). Such models are designed with varied degrees of empiricism assuming ET is primarily controlled by available energy and water (Zhang et al. 2004; Sun et al. 2006; Trabucco et al. 2008). Recent studies highlighted watershed characteristics as a critical parameter in explaining the effects of land cover change on water resources (Zhou et al. 2015; Liu et al. 2016).

Despite the impact of reforestation or afforestation on water resources are still debated, it is generally recognized that trees can reduce runoff at the small catchment scale but it links to the increased precipitation and water availability at large scale (Ellison et al. 2012). It remains a question of great interest to know the footprint that a forest operates in reducing runoff, thereby competing water resources with other non-forest ecosystems outside the forest boundary, or in enhancing precipitation for the benefit of improved local ecosystem productivity. Recent studies demonstrated divergent hydrological responses to large-scale afforestation and vegetation greening in China, such that in the Southwest China there has occurred large water deficiency ( $\mathrm{Li}$ 
et al. 2018). Revegetation in China's Loess Plateau has been cautioned for sustainable water resource limits (Feng et al. 2016). Research findings in China's Songnen Plain show that poplar afforestation has resulted in soil water shortage compared with adjacent regions (Wu et al. 2019).

In search of literature, most studies on forest water relations are concerned with stand level or regional scale evapotranspiration, and on matters of rainfall distributions in relation to forest type and structures. Examination of the implications of varying forest stands to catchment and watershed hydrological processes is almost an impossible task due to discrepancies in forest distribution in relation to landscape features and the complexity of waterflow movement and distribution. Unlike forest carbon sequestration, which can be effectively quantified by direct measurements at stand level and scaled up by remote sensing and modelling approaches (e.g. Law et al. 2004), quantification of forest hydrological processes at the stand level and scaling up to watershed scale by modelling requires the support of assumption-based parameterization and thus produces unquantifiable uncertainties (Ouyang et al. 2014).

\section{Linking carbon sequestration to water conservation in forestry research: a way forward}

While reviews of literature show that rich information are available for understanding forest carbon sequestration from local to global scales, relatively far less are known on hydrological regulations of forests and the impacts of afforestation on regional water resources. Existing studies of forest carbon sequestration and hydrological regulations mostly operate on different spatiotemporal scales and deploy different methodology and techniques, making the assessment of the trade-offs between forest carbon sequestration and water conservation a highly challenging task and fraught with great uncertainty. Seldomly, the dual ecosystem services of carbon sequestration and water conservation are considered in planning afforestation schemes and formulating management strategies of natural forest protection. It largely remains an open question the effective scale that forests are operated in achieving economical carbon benefit while maintaining the water regulation functionality of regional implications.

Traditional forest planning and management are largely focused on provisioning of wood products, in which trees are harvested at intervals and the risk of overconsumption of local water resources is largely removed during re-establishment and early development. Current demand for forest carbon sequestration services and biodiversity conservation calls for full forest protection and expanded planting, putting pressure on supply of water to various other usage by natural and social demands. Apart from land availability for afforestation among different land uses, allocation of water resources would be an important criterion in designing afforestation scheme.

There are many issues yet to be resolved by carefully developed research works. For the top-down planning of afforestation in regions where water availability is anticipated to be problematic, there comes the questions of how much and where to plant trees for given land availability, known environmental implications, and sustained regional development and livelihood. For local management considerations, the questions of what trees to plant and how to plant them prevail. Solution to the issues involves research support, consideration of socioeconomic preference, mechanism of eco-compensation or payment for ecosystem services (PESs), site selection and preparation, self-sustainability; of the established forests, tending and end uses of the planted trees, etc. To address these complex questions and issues, the existing studies and knowledge with narrowly focused scopes and objectives are insufficient. In view of the trend and societal perspective on forests, we propose an integrative research framework with dual consideration of forest carbon sequestration and water conservation, as illustrated in Fig. 2. The framework builds on collaborative research among the disciplines of forest regeneration, harvesting, and protection with unified experimental design and establishment of a global or regional forest research network. The central goal of the framework is to facilitate the establishment and management of planted forests for the social wellbeing and safeguarding biosecurity, aiming for delivery of balanced forest ecosystem services in carbon sequestration, water conservation, and other social values. Such an effort can help understand the scales that the ecosystem services of carbon sequestration and water cosocialnservation could be compromised under given climatic and geographical conditions.

Acknowledgements TJA Farooqi acknowledges the financial support of the China Scholarship Council as an academic exchange student in China.

Open Access This article is licensed under a Creative Commons Attribution 4.0 International License, which permits use, sharing, adaptation, distribution and reproduction in any medium or format, as long as you give appropriate credit to the original author(s) and the source, provide a link to the Creative Commons licence, and indicate if changes were made. The images or other third party material in this article are included in the article's Creative Commons licence, unless indicated otherwise in a credit line to the material. If material is not included in the article's Creative Commons licence and your intended use is not permitted by statutory regulation or exceeds the permitted use, you will need to obtain permission directly from the copyright holder. To view a copy of this licence, visit http://creativecommons.org/licenses/by/4.0/. 
Fig. 2 Scope of research supporting development of integrated forest carbon sequestration/water conservation framework
Integrated forest carbon sequestration/water conservation framework

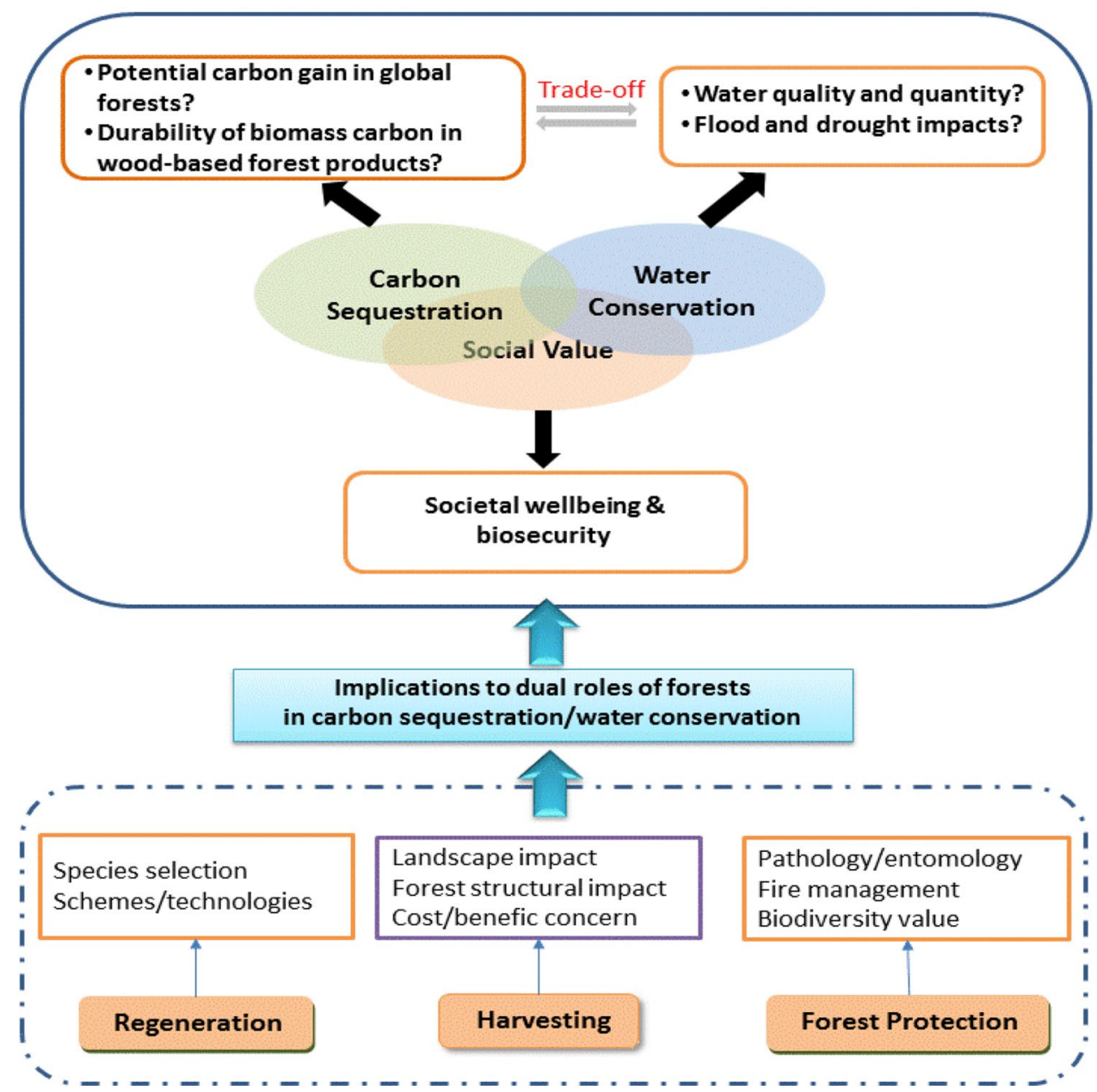

\section{References}

Boisvenue C, Bergeron Y, Bernier P, Peng CH (2012) Simulations show potential for reduced emissions and carbon stocks increase in boreal forests under ecosystem management. Carbon Manag 3:553-568

Bosch JM, Hewlett JD (1982) A review of catchment experiments to determine the effect of vegetation changes on water yield and evapotranspiration. J Hydrol 55:3-23

Brown AE, Podger GM, Davidson AJ, Dowling TI, Zhang L (2007) Predicting the impact of plantation forestry on water users at local and regional scales: an example for the Murrumbidgee River Basin, Australia. For Ecol Manag 251:82-93

Costanza R, d'Arge R, de Groot R, Farber S, Grasso M, Hannon B, Limburg K, Naeem S, O’Neil RV, Paruelo J, Raskin RG, Sutton $P$, van den Belt M (1997) The value of the world's ecosystem services and natural capital. Nature 387:253-260

Doelman JC, Stehfest E, van Vuuren DP, Tabeau A, Hof AF, Braakhekke MC et al (2020) Afforestation for climate change mitigation: potentials, risks and trade-offs. Glob Change Biol 26:1576-1591

Ellison D, Futter MN, Bishop K (2012) On the forest cover-water yield debate: from demand-to supply-side thinking. Glob Change Biol 18:806-820
Fang J, Chen A, Peng C, Zhao S, Ci L (2001) Changes in forest biomass carbon storage in China between 1949 and 1998. Science 292:2320-2322

Feng X, Fu BJ, Piao SL, Wang S, Ciais P, Zeng ZH et al (2016) Revegetation in China's Loess Plateau is approaching sustainable water resource limits. Nat Clim Change 6:11

Giardina CP, Ryan MG (2000) Evidence that decomposition rates of organic carbon in mineral soil do not vary with temperature. Nature 404:858-861

Haakana H, Huhta E, Hirvelä H, Packalen T (2020) Trade-offs between wood production and forest grouse habitats in two regions with distinctive landscapes. For Ecosyst 7:21

Jackson RB, Jobbágy EG, Avissar R, Roy SB, Barrett DJ, Cook CW et al (2005) Trading water for carbon with biological carbon sequestration. Science 310:1944-1947

Law BE, Turner D, Campbell J, Sun OJ, Lefsky M, Guzy M, Van Tuyl S (2004) Disturbance and climate effects on carbon stocks and fluxes across the forested region of Oregon USA. Glob Change Biol 10:1429-1444

Lempriere TC, Kurz WA, Hogg EH, Schmoll C, Rampley GJ, Yemshanov D et al (2013) Canadian Boreal forests and climate change mitigation. Environ Rev 21:293-321 
Li Y, Piao SL, Li LZX, Chen AP, Wang XH, Ciais P et al (2018) Divergent hydrological response to large-scale afforestation and vegetation greening in China. Sci Adv 4:5

Li XH, Farooqi TJA, Chao Jiang, Liu SR, Sun OJ (2019) Spatiotemporal variations in productivity and water use efficiency across a temperate forest landscape of Northeast China. For Ecosyst 6:22

Liu W, Wei X, Li Q, Fan H, Duan H, Wu J et al (2016) Hydrological recovery in two large forested watersheds of southeastern China: the importance of watershed properties in determining hydrological responses to reforestation. Hydrol Earth Syst Sci 20:4747-4756

Lv HL, Wang WJ, He XY, Wei CH, Xiao L, Zhang B, Zhou W (2018) Association of urban forest landscape characteristics with biomass and soil carbon stocks in Harbin City, Northeastern China. PeerJ 6:e5825

Malmer A, Murdiyarso D, Bruijnzeel LA, Ilstedt U (2010) Carbon sequestration in tropical forests and water: a critical look at the basis for commonly used generalizations. Glob Chang Biol 16:599-604

Matyas C, Sun G (2014) Forests in a water limited world under climate change. Environ Res Lett 9:085001

Medlyn BE (1998) Physiological basis of the light use efficiency model. Tree Physiol 18:167-176

Noormets A, Epron D, Domec JC, McNulty SG, Fox T, Sun G, King JS (2015) Effects of forest management on productivity and carbon sequestration: a review and hypothesis. For Ecol Manag 355:124-140

Ouyang S, Puhlmann H, Wang S, von Wilpert K, Sun OJ (2014) Parameter uncertainty and identifiability of a conceptual semi-distributed model to simulate hydrological processes in a small headwater catchment in Northwest China. Ecol Process 3:14

Pan Y, Birdsey RA, Fang J, Houghton R, Kauppi PE, Kurz WA et al (2011) A large and persistent carbon sink in the world's forests. Science 333:988-993

Pregitzer KS, Euskirchen ES (2004) Carbon cycling and storage in world forests: biome patterns related to forest age. Glob Change Biol 10:2052-2077

Schuur EAG, Chadwick OA, Matson PA (2001) Carbon cycling and soil carbon storage in mesic to wet Hawaiian montane forests. Ecology 82:3182-3196

Schwärzel K, Zhang LL, Montanarella L, Wang YH, Sun G (2020) How afforestation affects the water cycle in drylands: a process-based comparative analysis. Glob Chang Biol 26:944-959

Sollins P, Homann P, Caldwell BA (1996) Stabilization and destabilization of soil organic matter: mechanisms and controls. Geoderma 74:65-105

Sun WL, Liu XH (2020) Review on carbon storage estimation of forest ecosystem and applications in China. For Ecosyst 7:4

Sun OJ, Campbell J, Law BE, Wolf V (2004) Dynamics of carbon storage in soils and detritus across chronosequences of different forest types in the Pacific Northwest, USA. Glob Change Biol 10:1470-1481

Sun G, Zhou G, Zhang Z, Wei X, McNulty SG, Vose JM (2006) Potential water yield reduction due to forestation across China. J Hydrol 328:548-558

Sun XL, Tang ZX, Ryan MG, You YM, Sun OJ (2019) Changes in soil organic carbon contents and fractionations of forests along a climatic gradient in China. For Ecosyst 6:1

Tang X, Zhao X, Bai Y, Tang Z, Wang W, Zhao Y et al (2018) Carbon pools in China's terrestrial ecosystems: new estimates based on an intensive field survey. Proc Natl Acad Sci 115:4021-4026

Temperli C, Blattert C, Stadelmann G, Brändli UB, Thürig E (2020) Trade-offs between ecosystem service provision and the predisposition to disturbances: a NFI-based scenario analysis. For Ecosyst 7:27

Timothy D, Onisimo M, Cletah S, Adelabu S, Tsitsi B (2016) Remote sensing of aboveground forest biomass: a review. Trop Ecol $57: 125-132$
Trabucco A, Zomer RJ, Bossio DA, van Straaten O, Verchot LV (2008) Climate change mitigation through afforestation/reforestation: a global analysis of hydrologic impacts with four case studies. Agric Ecosyst Environ 126:81-97

Tucker CJ, Sellers PJ (1986) Satellite remote sensing of primary production. Int J Remote Sens 7:1395-1416

Vashum KT, Jayakumar S (2012) Methods to estimate above-ground biomass and carbon stock in natural forests-a review. J Ecosyst Ecogr $2: 1-7$

Wang WJ, Qiu L, Zu YG, Su DX, An J, Wang HY et al (2011) Changes in soil organic carbon, nitrogen, $\mathrm{pH}$ and bulk density with the development of larch (Larix gmelinii) plantations in China. Glob Chang Biol 17:2657-2676

Wang WJ, Wang HM, Zu YG (2014) Temporal changes in SOM, N, $\mathrm{P}, \mathrm{K}$, and their stoichiometric ratios during reforestation in China and interactions with soil depths: importance of deep-layer soil and management implications. For Ecol Manag 325:8-17

Wang H, Liu SR, Chang SX, Wang JX, Shi ZM, Huang XM et al (2015) Soil microbial community composition rather than litter quality is linked with soil organic carbon chemical composition in plantations in subtropical China. J Soils Sediments 15:1094-1103

Wang WJ, Lu JL, Du HJ, Wei CH, Wang HM, Fu YJ, He XY (2017) Ranking thirteen tree species based on their impact on soil physiochemical properties, soil fertility, and carbon sequestration in Northeastern China. For Ecol Manag 404:214-229

Wang H, Liu SR, Song ZC, Yang YJ, Wang JX, You YM et al (2019a) Introducing nitrogen-fixing tree species and mixing with Pinus massoniana alters and evenly distributes various chemical compositions of soil organic carbon in a planted forest in southern China. For Ecol Manag 449:117477

Wang Q, Wang WJ, He XY, Zhou W, Zhai C, Wang PJ et al (2019b) Urbanization-induced glomalin changes and their associations with land-use configuration, forest characteristics, and soil properties in Changchun, Northeast China. J Soils Sediments 19:2433-2444

Wang Q, Zhang D, Zhou W, He XY, Wang WJ (2020) Urbanization led to a decline in glomalin-soil-carbon sequestration and responsible factors examination in Changchun, Northeastern China. Urban For Urban Green 48:126506

Wu Y, Wang Q, Wang HM, Wang WJ, Han SJ (2019) Shelterbelt poplar forests induced soil changes in deep soil profiles and climates contributed their inter-site variations in dryland regions, northeastern China. Front Plant Sci 10:220

Wu X, Shen WJ, Guo B, Tao FL (2020) Large spatial variations in the distributions of and factors affecting forest water retention capacity in China. Ecol Indic 113:106152

Yang YB, Lv HL, Fu YJ, He XY, Wang WJ (2019) Associations between road density, urban forest landscapes, and structural-taxonomic attributes in northeastern China: decoupling and implications. Forests 10:58

You YM, Wang J, Huang XM, Tang ZX, Liu SR, Sun OJ (2014) Relating microbial community structure to functioning in forest soil organic carbon transformation and turnover. Ecol Evol 4:633-647

Yu Z, Liu S, Wang J, Wei A, Schuler J, Sun P, Harper R, Zegre N (2019) Natural forests exhibit higher carbon sequestration and lower water consumption than plantation forests in China. Glob Change Biol 25:68-77

Zhai C, Wang WJ, He XY, Zhou W, Xiao L, Zhang B (2017) Urbanization drives SOC accumulation, its temperature stability and turnover in forests, northeastern China. Forests 8:e130

Zhang L, Hickel K, Dawes WR, Chiew FHS, Western AW, Briggs PR (2004) A rational function approach for estimating mean annual evapotranspiration. Water Resour Res 40:W02502

Zhang D, Wang WJ, Zheng HF, Ren ZB, Zhai C, Tang Z (2017a) Effects of urbanization intensity on forest structural-taxonomic attributes, landscape patterns and their associations in Changchun, Northeast 
China: implications for urban green infrastructure planning. Ecol Indic 80:286-296

Zhang MF, Liu N, Harper R, Li Q, Liu K, Wei XH et al (2017b) A global review on hydrological responses to forest change across multiple spatial scales: importance of scale, climate, forest type and hydrological regime. J Hydrol 546:44-59

Zhao SQ, Liu SG, Zhou DC (2016) Prevalent vegetation growth enhancement in urban environment. Proc Natl Acad Sci 113:6313-6318
Zhou G, Wei X, Chen X, Zhou P, Liu X, Xiao Y et al (2015) Global pattern for the effect of climate and land cover on water yield. Nat Commun 6:5918

Zhou XL, Lei XD, Liu CX, Huang HB, Zhou C, Peng CH (2019) Reestimating the changes and ranges of forest biomass carbon in China during the past 40 years. For Ecosyst 6:51

Publisher's Note Springer Nature remains neutral with regard to jurisdictional claims in published maps and institutional affiliations. 